Edited by E. Rominger it was written and compiled by four paediatricians with the intention of helping the clinician in hospital and his colleagues in practice with the correct interpretation of organ function tests and the results of essential laboratory investigations. Stress has, therefore, been laid on the range of normal values and discussion of the factors influencing them, in addition to the exposition of pathological findings.

The content is divided into four chapters: metabolic investigations; organ function tests; coagulation tests and investigations of the corpuscular elements of the blood; and growth and development. The last chapter contains a weight chart for premature infants (according to Holt), somatograms, tables for head and chest circumferences, ossification tables for the assessment of bone age and a brief review of dwarfism.

The first three chapters contain a great deal of useful information which is set out clearly in a pleasantly readable style. The sentences are short, the meaning precise without being epigrammatic. A number of tests are given with details of method and others where the technique is not mentioned but with an adequate evaluation of results. Although it was probably not intended to produce a comprehensive volume certain omissions are regrettable. The xylose absorption test, for instance, is not mentioned, nor are means of assessing disturbances of tryptophane metabolism. Although tryptophane occurs in a table of disturbances of amino acid metabolism, it is not to be found in the index.

The haemoglobinopathies have been ignored, except for haemoglobin $\mathrm{F}$ and its occurrence in thalassaemia, and are also omitted from the index. Assessment of labyrinthine, visual, and auditory sensations are rather unexpectedly included among the organ function tests. The function of the kidneys and endrocrine organs are fully dealt with, but the chapter on growth and development is the weakest part of the book and has little more to offer than any standard textbook of paediatrics. The inadequacy of the index is sometimes infuriating and will need a thorough overhaul in the next edition, which this book certainly deserves.

Pathologie und Klinik in Einzeldarstellungen. Band XIII : Normale und Anomale Menschliche Hämoglobine. By Hans Rudolf Marti. Edited by R. Hegglin, F. Leuthardt, R. Schoen, H. Schwiegk, and H. U. Zollinger. (Pp. viii $+197 ; 74$ figures +11 tables. DM.48.) Berlin, Göttingen, and Heidelberg: Springer-Verlag. 1963.

This monograph gives a complete account of our knowledge of human haemoglobin, its molecular structure, its function, and its alterations, be they primary changes in the globin moiety or secondary changes in the haem. The author is a clinician and a well-known research worker in this discipline. Thus he deals also with enzymes of the red cell, and their influences on haemoglobin stability, all of them necessary for the normal life span of the erythrocyte, and with laboratory methods. A special section is devoted to thalassaemia, its pathogenesis and its clinical and laboratory diagnosis. Interwoven are personal observations, and one reads with interest that Dr. Marti has encountered much thalassaemia in Switzerland, and has identified amongst his patients at the Medical Polyclinic of Basel University haemoglobins. Bart's, H, I, S, Zürich, E, C, and M. The chapters on laboratory methods form one of the best collections published so far of simple yet reliable instructions on how to deal with virtually every diagnostic problem. The detailed list of references, all with full titles, completes the usefulness of this monograph as a textbook, a work of reference, and a bench book for the laboratory.

\section{Control of Glycogen Metabolism: Ciba Foundation} General Symposium. Consulting Editor: W. J. Whelan. Editor for the Ciba Foundation: MARGareT P. Cameron. (Pp. xiv $+434 ; 72$ figures + tables. 60s.) London: Churchill. 1964.

This latest symposium in the series promoted by the Ciba Foundation is concerned with the metabolism of glycogen, a topic as important as any previous one. It is of especial interest to paediatricians since the glycogen storage diseases are fully discussed. All clinicians must nowadays be in part biochemists, and this applies particularly to paediatricians who see the hereditary metabolic diseases in their earliest phase and who should. therefore be particularly aware of them. They have a great advantage over the clinician who is concerned only with adult patients and who may at best see these disorders in an advanced state, with secondary complications. obscuring the initial onset. Indeed, many children with hereditary metabolic disease may never reach adult life, and the paediatrician can contribute more than any other clinician to our knowledge in this field.

The subject matter of this volume is divided into three sections. The first, occupying about half the text, deals with the basic processes of glycogen metabolism and is a description, fascinating in its complexity, of the properties. and characterization of the enzymes concerned in the synthesis and degradation of glycogen. All the papers are lucidly written and, though hard going biochemically, are not so involved as to be beyond the comprehension of the modern paediatrician. It is not obvious why Dahlqvist's paper on the intestinal absorption of disaccharides is in this section, or indeed in the symposium at all, since its link with glycogen is tenuous, but we should be grateful for its inclusion because of its importance in paediatrics. The second section deals with the regulation of glycogen metabolism in liver and muscle, particularly via phosphorylase, and the effect of insulin.

The last part, comprising about one-quarter of the volume, deals with the glycogen storage diseases. The past few years have seen great progress in the biochemical understanding of these conditions, and this has enabled us to classify them on biochemical rather than on clinical grounds, surely a more rational basis for classification since, as one author observes, similar clinical manifestations may arise from differing metabolic disturbances, and, on the other hand, similar enzyme defects may give rise to considerable variability in clinical expression. 
After an introductory paper on the clinical manifestation of glycogen storage disease, there are separate communications on Types I, II, and V, and another on Types III, IV, and VI. Though not strictly a glycogen storage disease, glycogen synthetase deficiency is also described. All these papers are of an extremely high standard, which is not surprising since the authors are the foremost in their respective fields. The discussion following each paper is a model of what such discussions should be (but only infrequently are): illuminating, sharp, and clear, and giving an indication of the path ahead. This volume can be unreservedly recommended.

Disorders of Voluntary Muscle. Edited by JoHN N. WALton. (Pp. $x+628 ; 143$ figures + tables. 100s.) London: J. \& A. Churchill. 1964.

In his preface, Dr. John Walton writes: 'In designing the present volume, therefore, it has been my aim and that of the other twenty-four contributors, each an acknowledged expert in the field, to give an up-to-date and comprehensive yet precise view of disorders of muscle from several stand-points. The book is aimed primarily at the clinician, whether he be a general physician, paediatrician or neurologist, or post-graduate student studying for a higher examination or any doctor wishing to expand his knowledge of this group of disorders.' It must be said at once that the Editor has achieved exactly what he set out to do. The book is comprehensive in the sense that the anatomy, physiology, pathology, and diseases affecting muscle are all discussed by experts who have succeeded to a remarkable extent in covering recent advances in knowledge and in giving copious references. This reviewer found the chapters on the pathology of muscular disorders particularly rewarding. Pearse's 'Histochemical Aspects of Muscle Diseases' and Pennington's 'Biochemical Aspects of Muscle Disease' for example, are remarkable reviews that repay detailed study. The chapters on electrodiagnosis are also excellent for they not only discuss methods of electrodiagnosis but also indicate when and how electrodiagnosis can be helpful in the clinical setting. In comparison, some of the chapters on clinical problems in muscle disease in the third part of the book seem to have rather little to say and that on 'Myopathies in Animals' hardly describes the clinical problems that are likely to be encountered frequently by those for whom the book was written. The chapter on polyneuropathies by Earl is rather sketchy; that on neuromuscular disorders of infancy by Tizzard inevitably contains little new; that by Kloepfer on genetic aspects of neuromuscular disease could have been expanded with advantage, for the large amount of information given in its 16 pages makes for rather heavy reading.

In general, however, there can be few criticisms of this excellent book which is beautifully printed and illustrated. It will be found useful by anybody interested in muscular disorders.

Tumoren im Kindesalter. Postgraduate Courses in Pediatrics. Vol. 13. Edited by E. Rossi. (Pp. 107; 24 figures +15 tables. S.Fr./DM.19.) Basel and New York: S. Karger. 1964.

This Swiss paperback contains 5 essays on childhood neoplasms, 2 in French and 3 in German. It will be useful to the paediatrician and the general pathologist but is too elementary for the paediatric pathologist and the paediatric surgeon.

In the first chapter the late Dr. Bodian gives a clear account of the classification, incidence, treatment, and survival rates of 1,162 neoplasms (excluding leukaemias) seen at Great Ormond Street. It is interesting to note that the percentage of deaths from neoplasia during childhood rose from $10 \%$ in 1949 to $20.3 \%$ in 1961 .

Schweisguth's account to some extent overlaps that of Bodian, though the approach is somewhat more clinical. There are some strange contradictions: in London, Wilms tumour not infrequently calcifies, yet practically never does so in Villejuif. Actinomycin D is useless at Great Ormond Street, but an excellent adjuvant in Berne and Boston. In London, no children with osteosarcoma survive, but 5 to $19 \%$ do so in Berne.

There follows an outline of the role of surgery, either alone or in combination with other methods of attack. Most of the quoted results relate to American work.

Wagner and Kaser deal with the effect of chemotherapy on all types of childhood malignancies. This is the best section in the book. The team approach (surgeon, radiotherapist, chemotherapist, and histologist) is rightly stressed. Though it is encouraging that in $60 \%$ of cases chemotherapy is beneficial, the list of side-effects makes grim reading.

The last chapter deals very briefly with the excretion of catecholamines in neuroblastoma and phaeochromocytoma.

Three criticisms: there is too much overlap and the editor should try some radical surgery; only two of the five chapters have a bibliography; a 'recent-advancestype' of book is presumably meant for reference, yet this 35s. paperback showed signs of falling apart even after one reading.

\section{Donald Paterson Prize Essay}

A prize essay competition will be held, open to medical practitioners registered in the United Kingdom for not more than ten years. The value of the prize will be twenty-five pounds.

The subject of the essay shall be related to paediatrics but will be chosen individually by candidates. The essay shall consist substantially of unpublished work. Entry forms and further information may be obtained from the Secretary, British Paediatric Association, Institute of Child Health, Great Ormond Street, London W.C.1. The closing date for applications will be June 30, 1965. 